\title{
The combined effects of parental divorce and parental history of depression on cannabis use in young adults in France
}

Authors: Kwame S. Sakyi ${ }^{1}$, Maria Melchior ${ }^{2}$, Aude Chollet $^{2}$, Pamela J. Surkan ${ }^{1}$

\section{Author affiliations and contact information:}

${ }^{1}$ Social and Behavioral Interventions Program, Dept. of International Health, Johns Hopkins Bloomberg School of Public Health, 615 N. Wolfe Street, Baltimore, Maryland, 21205, USA; kss11@albion.edu and psurkan@jhsph.edu; phone: 410-502-7396, fax: 410-502-6733.

${ }^{2}$ INSERM U1018, Centre for Research in Epidemiology and Population Health, Epidemiology of occupational and social determinants of health, F-94807, Villejuif, France;

maria.melchior@inserm.fr and aude.chollet@inserm.fr; phone: +33 (0)1 777474 27; fax: +33

(0)1 77747403

Corresponding author: Social and Behavioral Interventions Program, Dept. of International Health, Johns Hopkins Bloomberg School of Public Health, 615 N. Wolfe Street, Baltimore, Maryland, 21205, USA; kss11@ @albion.edu; phone: 410-502-7396, fax: 410-502-6733

Word count: Abstract: 250

Text: 2,885

Tables: 3

Figures: 0 


\begin{abstract}
Background: The joint effects of multiple social risk factors, such as parental divorce and parental history of depression on substance use, have rarely been studied in young adult offspring.
\end{abstract}

Methods: We examined the combined effects of parental divorce and parental history of depression on current cannabis use among a community sample of young adults in France. Parental divorce was ascertained as divorce or separation before 2009. Parental history of depression based on parental reports of depression (1989-2009) and offspring reports of parental lifetime history of depression. Current cannabis use was defined as use at least once in the preceding 12 months. Data were analysed using multiple logistic regression models controlling for young adult and parental socio-demographic variables.

Results: Approximately one fourth of youth (23\%) reported consuming cannabis at least once in the past year. At the same time, $15 \%$ had parents who were divorced and $30 \%$ parents with a history of depression. The association between parental divorce and cannabis use in young adults was not statistically significant (Adjusted OR: 1.50; 95\% CI: 0.97-2.31). History of parental depression conferred a marginally statistically significant $42 \%$ higher odds of young adult cannabis use (Adjusted OR: 1.42; 95\% CI: 1.00-2.01). Young adults who experienced both parental history of divorce and depression were more than two times as likely to be current cannabis users compared to those who experienced neither of these (Adjusted OR:2.38; 95\% CI:1.26-4.48).

Conclusion: Our findings highlight the critical importance of considering familial context in understanding cannabis use in young adults.

Keywords: cannabis use; young adults; parental divorce; parental history of depression 


\section{Introduction}

Cannabis is the most frequently used illegal drug in industrialized countries (European Monitoring Center for Drugs and Drug Addition, 2010). In France, cannabis use levels are among the highest in Europe and comparable to rates observed in the US (Legleye et al., 2009; Melchior et al., 2008; Redonnet et al., 2011). In a large, nationally representative sample of French youth, aged $12-26$ years, $42 \%$ of the youth sampled had used cannabis (Melchior et al., 2008).

This high usage of cannabis is a concern, as a number of studies have demonstrated adverse effects of cannabis on respiratory function (Aldington et al., 2007; Taylor et al., 2000; Taylor et al., 2002), psychosocial wellbeing (Arseneault et al., 2002; Hall and Solowij, 1998; McGee et al., 2000; Patton et al., 2002), traffic injuries (Asbridge et al., 2005; Gerberich et al., 2003; Ramaekers et al., 2004) and serious mental disorders (Arseneault et al., 2002). In a metaanalysis of longitudinal studies, lifetime cannabis use was associated with a $41 \%$ increased risk of any psychotic outcome (Moore et al., 2007). In a sample of 10,748 French drivers, cannabis users were about three times more likely to be responsible for vehicle crashes when compared to non-users (Laumon et al., 2005).

To understand familial risk and protective factors associated with cannabis use, a number of longitudinal and cross-sectional studies have examined parental marital status (Amato and Keith, 1991; Hayatbakhsh et al., 2006; Ledoux et al., 2002; Needle et al., 1990), parental mental health status, (Weissman et al., 1997; Cortes et al., 2009) and their respective associations with illegal substance use (including cannabis) in children. These studies have largely focused on adolescents (Cortes et al., 2009; Hayatbakhsh et al., 2006; Ledoux et al., 2002; Needle et al., 
1990; Neher and Short, 1998) compared to young adults (Leib et al., 2002; Hayatbakhsh et al., 2009).

In these studies, parental history of depression and parental divorce has been shown to be independently associated with illicit drug use in children. In a cross-sectional community sample of adolescents and young adults, offspring of parents with major depressive disorders had a $40 \%$ higher risk of illicit drug use (including cannabis) compared to those whose parents did not have any depressive disorders (Leib et al., 2002). Cortes et al. (2009) reported that similar to major depression, maternal depressive mood was also significantly associated with adolescent cannabis use.

In a longitudinal survey, Needle et al. (1990) found that offspring of parents who were divorced reported increased rates of overall drug involvement than those whose parents were married. In France, Ledoux et al. (2002) also observed that offspring of parents from non-intact homes were more likely to report higher use of cannabis compared to those who did not come from such a home. The association between parental divorce and illicit drug use has been pointed out to be weak (Amato and Keith, 1991).

Our work seeks to fill the gap identified in the literature on cannabis use and contribute to a better understanding of the familial environment as a contributor to the parent-child transactional processes underscoring substance use (Kumpfer and Bluth, 2004). Currently, the effect of both parental divorce and parental history of depression on cannabis use has not been examined. The combined effect of these two parental variables on cannabis use in young adults has only been speculated (Hayatbakhsh et al., 2006). The aim of this study was to evaluate the individual and combined effect of parental divorce and parental history of depression on current cannabis use in a community sample of French young adults. We hypothesized that each would 
be independent risk factors, and that young adults who have been exposed to both parental divorce and parental history of depression will be more likely to be current users of cannabis compared to those who have not had these two risk factors.

\section{Methods}

The Trajectoires Épidémiologiques en Population (TEMPO) study based in France began in 2009 among young adults aged 22 to 35 years. These young adults are children of participants of the ongoing GAZEL cohort study (1989-2009) (Goldberg et al., 2007). In 1991, all GAZEL participants took part in the GAZEL Youth Study, which aimed to assess the prevalence of mental health problems and access to health care in children (Fombonne and Vermeersch, 1997). The original sample included one 4-16 year old child per family and was stratified in order to match the number of children per family and socio-economic position of children in France. In 2009, all GAZEL Youth Study participants were invited to take part in the TEMPO study via their parents.

A total of 1,103 out of 2,498 eligible young adults (44.2\%) returned the study questionnaire forwarded by their parent, a response rate that is comparable to other mental health surveys conducted in France (Alonso et al., 2004). Of the 2,498 eligible youth, four were too ill or disabled to answer and 16 had died since 1991. Approximately $27 \%$ of the non-respondents had a parent who had not completed the GAZEL questionnaire in 2009; thus it is unlikely that parents of these children forwarded the TEMPO questionnaire to their children, partially explaining non-response. Of the non-respondents, $28.1 \%$ indicated they were not interested in the study and $6.9 \%$ could not be reached (e.g. due to lack of contact with their parents). Nonresponse was $8.9 \%$ when the parent had forwarded the study questionnaire. Respondents were more likely to be female, have high socio-economic position, and higher education. They were 
also less likely to come from divorced parent households and have depressed parents or parents with alcohol problems. In terms of ethical approval, the TEMPO study was approved by the Comité Consultatif sur le Traitement de l'Information en Matière de Recherche dans le domaine de la Santé (CCTIRS) and by the French National Committee for Data Protection (CNIL: Commission Nationale Informatique et Liberté).

The outcome of interest, current cannabis use, was assessed by asking participants the number of times they had used cannabis in the 12 months prior to the 2009 survey. Participants who had consumed cannabis at least once were classified as current cannabis users.

Parental divorce/separation and parental depression were assessed using data from both the GAZEL and the TEMPO studies. Parental divorce/separation (referred to as parental divorce from here onward) was ascertained as the occurrence of divorce or separation before and including 2009, as reported by the parents in the yearly GAZEL study questionnaire. Parental history of depression was based on 1) at least two parental self-reports of depression or treated depression in the yearly GAZEL study questionnaire between 1989 and 2009, and 2) offspring reports of parental history of depression on a questionnaire based on the Family Interview for Genetic Studies (FIGS) in the TEMPO 2009 survey.

Socio-demographic variables included age (used as a continuous variable), sex (male vs. female), living with partner (yes vs. no), socio-economic position was ascertained based on educational status, occupational level, unemployment, and job instability (dichotomized at the bottom quartile of the distribution into low vs. intermediate/high) (Melchior et al., 2007), academic difficulties (dichotomized as having repeated at least two grades at school vs. less than two) and emotional stability was measured using the Ten Item Personality Inventory (TIPI) 
based on a scale ranging from 1("not at all") to 7 ("yes, very") as a continuous variable (Rammstedt and John, 2007).

Participants' psychopathology was assessed using the Young Adult Self-Report from the ASEBA (Achenbach System of Empirically-Based Assessment) system (Achenbach, 2007). This largely used psychometric instrument assesses youth emotional and behavioral problems over a six months period and has previously been validated in French (Fombonne, 1991; Fombonne, 1994; Stranger et al., 1994). Young adults' externalizing symptoms, most likely to be related to cannabis use, were assessed through a measure of aggressive behaviour, based on 15 items which, according to previously published guidelines were summed and standardized (Achenbach, 2007).

Parental variables included parental sex (male vs. female) and parental smoking assessed through parental self-report in the yearly GAZEL study questionnaires between 1989 and 2009. This was dichotomized into two groups: yes (defined as smoked in any one assessment year) and no (never smoked).

\subsection{Statistical analysis}

Descriptive statistics were calculated including bivariate chi-square tests for the categorical variables and t-tests for the continuous variables. Then, bivariate logistic regression models were used to test associations between each variable and the outcome of current cannabis use. Multiple logistic regression was used to assess the relationship between the parental history of depression and divorce and current cannabis use, adjusting for socio-demographic characteristics that were significant in bivariate tests (age, gender, academic difficulty, socioeconomic and civil status), along with history of parental smoking, and sex of the parent. 
In our final model, history of parental divorce and parental depression variables were combined into four groups: 1) no parental divorce/no parental depression, 2) no parental divorce/ parental depression, 3) parental divorce/ no parental depression, and 4) parental divorce/parental depression. There were 61 missing values after this categorization, mainly from the parental divorce variable. Participants with missing data on parental divorce or parental history of depression did not significantly vary from the rest of the sample in terms of current use of cannabis, socio-economic position, living with partner or age. The final model included our combined parental divorce and parental depression exposure variable in relation to participants' current cannabis use, while making the same adjustments. The Hosmer-Lemshowe chi-square goodness of fit test was used to check the fit of the model. The model was judged to be a good fit if the p-value associated with this test was greater than 0.05. All data was analyzed using Stata 11 (StataCorp, 2009).

\section{Results}

Participant characteristics are presented in Table 1. Our sample had a mean age of 29 years and approximately 59\% were female. Fifteen percent had parents who were divorced and 30\% had parents with a history of depression. Young adult mean age at the time of parental divorce, excluding those whose parents were divorced in 1989, was 17 years (range 3-32). Six percent of young adults who had parents with a history of depression were also divorced. Sixty-one percent of young adults experienced neither parental divorce nor parental history of depression. Twenty-three percent of youth reported consuming cannabis at least once in the past year (data not shown). Crude analyses showed that male gender, low SES, not living with a spouse/partner, younger age, academic difficulties, parental divorce and parental depression were related to a higher odds of being a current cannabis user ( $\mathrm{p}<0.05$ for all). When comparing young adults with parents with no 
history of divorce and depression to those who had both, young adults who had parents with both problems were at higher risk of current cannabis use in crude analyses (Unadjusted OR=2.31; 95\% CI: $1.31-4.06 ; \mathrm{p}<0.01)$.

Parental history of divorce fell short of statistically significance but was associated with a $50 \%$ increased odds of being a current cannabis user among the young adults, after controlling for socio-demographic factors (age, sex, academic difficulties, SES, and living with partner) and parental variables (parental gender and parental smoking) (Adjusted OR=1.50, 95\% CI: 0.97-2.31; $\mathrm{p}=0.07$; Table 2), The association between history of parental depression and young adult cannabis use was marginally statistically significant (Adjusted OR=1.42 95\% CI 1.00-2.01, p=0.05; Table 2). However, young adults who experienced both parental history of divorce and depression were more than two times as likely to be current users of cannabis compared to those who have experienced neither of these, after controlling for the same factors (Adjusted OR: 2.38; 95\% CI: 1.26-4.48; $\mathrm{p}=0.01$ ), (Table 3). Sub-analyses of age at divorce and current cannabis use were performed, but showed no significant associations (Data not shown).

\section{Discussion}

To our knowledge, to date no study has examined the co-morbidity of parental divorce and parental history of depression on cannabis use in young adults. Our primary hypothesis was that young adults who have experienced both parental divorce and parental history of depression are more likely to use cannabis in young adulthood compared to those who have experienced neither of these. Our main finding is that young adults who experience both parental divorce and parental history of depression have a 2.38 times greater odds of being current cannabis users compared to those who have experienced neither of these, after controlling for socio-demographic factors and 
parental variables. The combined effect of these two risk factors appears to be stronger than either of the two factors alone.

Parental divorce has been consistently shown in several studies to contribute to depression (Breslau et al., 2011; Bruce and Kim, 1992) and poor psychological well-being for divorced couples (Booth and Amato, 1991). Offspring of depressed parents are also more likely to experience depression themselves (Beardslee et al., 1998; Leib et al., 2002; Peisah et al., 2004; Skeer et al., 2009), which has been shown as a risk factor for using illegal drug use, including cannabis (Liang et al., 2010).

Moreover, parental depression may also compound the undesirable stressors associated with parental divorce for both parents and adult offspring (Booth and Amato, 1991; Timko et al., 2009). This compounded stress may contribute to the use of illegal drugs as a coping mechanism during the adolescent years of the young adults in our study (the average age of parental divorce was 17 years), which then have effects on substance use that extend into adulthood (Fawzy et al., 1983; Needle et al., 1990; Regan and Beaver, 2010). A study of non-clinical depression in mothers showed that it impacted adolescent offsprings' initiation of cannabis use (Cortes et al., 2009).

We did not find strong statistically independent effects of parental divorce and parental history of depression on current cannabis use among young adults. Our lack of a clear independent effect of parental divorce on current cannabis use among young adult offspring differs from what has typically been reported in the literature (Barrett and Turner, 2006; Hayatbakhsh et al., 2006; Hayatbakhsh et al., 2009; Ledoux et al., 2002). This difference may due to: 1) differences in level of control for potential confounders, 2) the age of the population we studied, or 3) possibly that parental divorce may not independently explain the use of 
cannabis among young adults in France. It is also possible that we may have lacked sufficient power to reach statistical significance.

Our study has a number of strengths. Co-occurring childhood adversities provide a better estimate and picture of the association between familial factors and cannabis use compared to individual exposures (McLaughlin et al., 2010 and Green et al., 2010). To our knowledge, estimates of the joint effects of parental divorce and parental history of depression on young adults current cannabis use have not been previously reported. Additionally, because they are of particular interest we focused on a community of young adults in France. A significant fraction of them continue to use illegal drugs (Melchior et al., 2008) and the young adult age is a period where the use of cannabis peaks (Schulenberg et al., 2005). We were able to use longitudinal measures of history of parental depression and smoking as well as divorce reported at the time it occurred by linking data from TEMPO to the original GAZEL cohort study. Young adults are usually difficult to survey and it is uncommon to have longitudinal measures of familial and childhood characteristics of young adults (Redonnet et al., 2011). Our assessment of parental history of depression included both parents and was non-clinically based, which make our results more generalizable.

Despite these strengths, our study has limitations. Parental history of depression was assessed based on self-report as well as offspring reports of their parents having a history of depression. Thus, comparisons of or findings on parental history of depression on current cannabis use to other studies using clinically diagnosed depression are not always straightforward (Peisah et al., 2004; Weissman et al., 1997). However, we speculate that the association between clinical depression and offspring cannabis use may be stronger than reported in the present study. Non-participants disproportionately had lower socio-economic position, thus we lack information on youth experiencing socio-economic hardship (Redonnet et al., 
2011). In spite of this, the overall prevalence of cannabis use in our study is similar to national estimates (Institut National de la Statistique et des Études Économiques, 2009; Redonnet et al., 2011) Therefore, it remains to be seen if the association between parental divorce and parental history of depression is generalizable to youth of lower socio-economic backgrounds.

Finally, we did not have data on parental cannabis use or young adult depressive symptoms, which have been shown in some studies to affect cannabis use in offspring of parents affected by divorce or depression (Cortes et al., 2009; Hayatbakhsh et al., 2006). However, we controlled for parental cigarette smoking, which may be a proxy indicator of parental substance dependence (Degenhardt et al., 2001; Martinez-Ortega et al., 2006). Parental cigarette smoking, especially in mothers, has been shown to predict cannabis use in young adults (Hayatbakhsh et al., 2007).

The main finding from our present study suggests the critical importance of considering familial contextual factors in understanding cannabis use in young adults. Owing to the elevated likelihood of cannabis use among those who experience parental divorce and parental history of depression compared to those who do not have such an experience, it is important for preventive measures to especially focus on young adults who have these risk factors combined. 


\section{References}

Achenbach, T.M., 2007. Achenbach System of Empirically-Based Assessment. Available at: http://www.aseba.org/ [accessed on [January 20, 2008]]

Aldington, S., Williams, M., Nowitz, M., Weatherall, M., Pritchard, A., McNaughton, A., McNaughton, A., Robinson, G., Beasley, R., 2007. Effects of cannabis on pulmonary structure, function and symptoms. Thorax. 62, 1058-1063.

Alonso, J., Angermeyer, M.C., Bernert, S., Bruffaerts, R., Brugha, T.S., Bryson, H., de Girolamo, G., Graaf, R., Demyttenaere, K., Gasquet, I., 2004. Sampling and methods of the European Study of the Epidemiology of Mental Disorders (ESEMeD) project. Acta Psychiatr Scand Suppl. 420, 8-20.

Amato, P., Keith, B., 1991. Parental divorce and well-being of children: a meta analysis. Psychological Bulletin. 110, 26-46.

Arseneault, L., Cannon, M., Poulton, R., Murray, R., Caspi, A., Moffitt, T.E., 2002. Cannabis use in adolescence and risk for adult psychosis: longitudinal prospective study. BMJ. 325, 1212-1213.

Asbridge, M., Poulin, C., Donato, A., 2005. Motor vehicle collision risk and driving under the influence of cannabis: evidence from adolescents in Atlantic Canada. Accident Analysis and Prevention. 37, 1025-1034.

Barrett, A.E., Turner, J.R., 2006. Family structure and substance use problems in adolescence and early adulthood: examining explanations for the relationship. Addiction. 101, 109-120.

Beardslee, W.R., Versage, E.M., Gladstone, T.R.G., 1998. Children of affectively ill patients: A review of the past 10 years. Journal of The American Academy of Child and Adolescent. 37, 1134-1141.

Booth, A., Amato, P., 1991. Divorce and psychological stress. Journal of Health and Social Behavior. 32, 396-407.

Breslau, J., Miller, E., Jin, R., Sampson, N.A., Alonso, J., Andrade, L.H., Bromet, E.J., de Girolamo, G., Demyttenaere, K., Fayyad, J., Fukao, A., Gălăon, M., Gureje, O., He, Y., Hinkov, H.R., Hu, C., Kovess-Masfety, V., Matschinger, H., Medina-Mora, M.E., Ormel, J., Posada-Villa, J., Sagar, R., Scott, K.M., Kessler, R.C., 2011. A multinational study of mental disorders, marriage, and divorce. Acta Psychiatrica Scandinavica. 1-13.

Bruce, M.L., Kim, K.M., 1992. Differences in the effects of divorce on major depression in men and women. The American Journal of Psychiatry. 149, 914-917. 
Cortes, R.C., Fleming, C.B., Mason, W.A., Catalano, R.F., 2009. Risk factors linking maternal depressed mood to growth in adolescent substance use. Journal of Emotional and Behavioral Disorders. 17, 49-64.

Degenhardt, L., Hall, W., Lynskey, M., 2001. The relationship between cannabis use and other substance use in the general population. Drug Alcohol Depend. 64, 319-327.

European Monitoring Center for Drugs and Drug Addition, 2010. Annual Report 2010: The state of the drugs problem in Europe. European Monitoring Center for Drugs and Drug Addition, Lisbon, Portugal. Available at http://www.emcdda.europa.eu/online/annual-report/2010 [accessed on [October 18, 2011]]

Fawzy, I.F., Coombs, R.H., Gerber, B., 1983. Generational continuity in the use of substances: The impact of parental substance use on adolescent substance use. Addictive Behaviors. 8, 109-114.

Fombonne, E., 1994. The Chartres Study: 1. Prevalence of psychiatric disorders among French school-age children. British Journal of Psychiatry. 164, 69-79.

Fombonne, E., 1991. The use of questionnaires in child psychiatry research: measuring their performance and choosing an optimal cut-off. Journal of Child Psychology and Psychiatry and Allied Disciplines. 32, 677-693.

Fombonne, E., Vermeersch, S., 1997. Children of the GAZEL Cohort: I--Prevalence of contacts with the medico-educational system for psychological reasons, and associated factors. Rev Epidemiol Sante Publique. 45, 29-40.

Gerberich, S.G., Sidney, S., Braun, B.L., Tekawa, I.S., Tolan, K.K., Quesenberry, C.P., 2003. Marijuana use and injury events resulting in hospitalization. Annals of Epidemiology. 13, 230-237.

Goldberg, M., Leclerc, A., Bonenfant, S., Chastang, J.F., Schmaus, A., Kaniewski, N., Zins, M., 2007. Cohort profile: the GAZEL study cohort. International Journal of Epidemiology. 36, 32-39.

Green, J., McLaughlin, K., Berglund, P., Gruber, M., Sampson, N., Zaslavsky, A., Kessler, R., 2010. Childhood adversities and adult psychopathology in the National Comorbidity Survey Replication (NCS-R) I: Associations with first onset of DSM-IV disorders. Arch Gen Psychiatry. 62, 113-123.

Hall, W., Solowij, N., 1998. Adverse effects of cannabis. Lancet. 352, 1611-1616.

Hayatbakhsh, M.R., Najman, J.M., Bor, W., Williams, G.M., 2009. Multiple risk factor model predicting cannabis use and use disorders: a longitudinal study. The American Journal of Drug and Alcohol Abuse. 35, 399-407. 
Hayatbakhsh, M.R., Najman, J.M., Jamrozik, K., Mamun, A.A., Williams, G.M., Alati, R., 2006. Changes in maternal marital status are associated with young adults' cannabis use: evidence from a 21-year follow-up of a birth cohort. International Journal of Epidemiology. 35, 673679.

Hayatbakhsh, M.R., Alati, R., Hutchinson, D.M., Jamrozik, K., Najman, J.M., Mamun, A.A., O'Callaghan, M., Bor, W., 2007. Association of maternal smoking and alcohol consumption with young adults' cannabis use: a prospective study. American Journal of Epidemiology. $166,592-598$.

Institut National de la Statistique et des Études Économiques., 2009. Une photographie du marché du travail en 2009. Available at:http://www.insee.fr/fr/themes/detail.asp?ref_id=ireec09\&page=irweb/eec09/dd/eec09_nat_chom.htm [accessed on [May 31, 2011]]

Kumpfer, K., Bluth, B., 2004. Parent/child transactional processes predictive of resilience or vulnerability to "substance abuse disorders". Subst Use Misuse. 39, 671-698.

Laumon, B., Gadegbeku, B., Martin, J-L., Biecheler, M-B., the SAM Group, 2005. Cannabis intoxication and fatal road crashes in France: population based case-control study. BMJ. $331,1371$.

Ledoux, S., Miller, P., Choquet, M., Plank, M., 2002. Family structure, parent-child relationships, and alcohol and other drug use among teenagers in France and UK. Alcohol and Alcoholism. 37, 52-60.

Legleye, S., Spilka, S., Le Nézet, O., Laffiteau, C., 2009. Les Drogues à 17 Ans. Résultats De l'Enquête ESCAPAD 2008. Available at: http://www.ofdt.fr/BDD/publications/docs/eftxstp6.pdf [accessed on [March 12, 2011]]

Leib, R., Isensee, B., Hofler, M., Pfiste, H., Wittchen, H., 2002. Parental major depression and the risk of depression and other mental disorders in offspring: a prospective-longitudinal community study. Archives of General Psychiatry. 59, 365-374.

Liang, W., Chikritzhs, T., Lenton, S., 2010. Affective disorders and anxiety disorders predict the risk of drug harmful use and dependence. Addiction. 106, 1126-1134.

Martı'nez-Ortega, J.M., Jurado, D., Martı'nez-Gonza'lez, M.A., Gurpegui, M., 2006. Nicotine dependence, use of illegal drugs and psychiatric morbidity. Addictive Behaviors. 31, 17221729 .

McGee, R., Williams, S., Poulton, R., Moffitt, T., 2000. A longitudinal study of cannabis use and mental health from adolescence to early adulthood. Addiction. 95, 491-605.

McLaughlin, K., Green, J., Gruber, M., Sampson, N., Zaslavsky, A., Kessler, R., 2010. Childhood adversities and adult psychiatric disorders in the National Comorbidity Survey 
Replication II. Associations with persistence of DSM-IV disorders. Arch Gen Psychiatry. 67, 124.-132.

Melchior, M., Moffitt, T.E., Milne, B.J., Poulton, R., Caspi, A., 2007. Why do children from socioeconomically disadvantaged families suffer from poor health when they reach adulthood? A life-course study. American Journal of Epidemiology. 166, 966-974.

Melchior, M., Chastang, J., Goldberg, P., Fombonne, E., 2008. High prevalence rates of tobacco, alcohol and drug use in adolescents and young adults in France: results from the GAZEL Youth study. Addictive Behaviors. 33, 122-133.

Moore, T.H.M., Zammit, S., Lingford-Hughes, A., Barnes, T.R.E., Jones, P.B., Burke, M., Lewis, G., 2007. Cannabis use and risk of psychotic or affective mental health outcomes: a systematic review. Lancet. 370, 319-328.

Needle, R.H., Su, S.S., Doherty, W.J., 1990. Divorce, remarriage, and adolescent substance use: a prospective longitudinal study. Journal of Marriage and Family. 52, 157-169.

Neher, L.S., Short, J.L., 1998. Risk and protective factors for children's substance use and antisocial behavior following parental divorce American Journal of Orthopsychiatry. 68, 154-161.

Patton, G.C., Coffey, C., Carlin, J.B., Degenhardt, L., Lynskey, M., Hall, W., 2002. Cannabis use and mental health in young people: cohort study. BMJ. 325, 1195-1198.

Peisah, C., Brodaty, H., Luscombe, G., Ansteyd, K.J., 2004. Children of a cohort of depressed patients 25 years later: psychopathology and relationships. Journal of Affective Disorders. $82,385-394$.

Ragan, D.T., Beaver, K.M., 2010. Chronic Offenders: A Life-Course Analysis of Marijuana Users. Youth \& Society. 42, 174-198.

Ramaekers, J.G., Berghaus, G., Van Laar, M., Drummer, O.H., 2004. Dose related risk of motor vehicle crashes after cannabis use. Drug and Alcohol Dependence . 73, 109-119.

Rammstedt, B., John, O.P., 2007. Measuring personality in one minute or less: a 10-item short version of the Big Five Inventory in English and German. Journal of Research in Personality. 41, 203-212.

Redonnet, B., Chollet, A., Fombonne, E., Bowes, L., Melchior, M., 2011. Tobacco, alcohol, cannabis and other illegal drug use among young adults: the socioeconomic context. Drug and Alcohol Dependence. 121, 231-239.

Schulenberg, J.E., Merline, A.C., Johnston, L.D., O'Malley, P.M., Bachman, J.G., Laetz, V.B., 2005. Trajectories of marijuana use during the transition to adulthood: the big picture based on national panel data. J Drug Issues. 35, 255-279. 
Skeer, M., McCormick, M.C., Normand, S.T., Buka, S.L., Gilman, S.E., 2009. A prospective study of familial conflict, psychological stress, and the development of substance use disorders in adolescence. Drug and Alcohol Dependence. 104, 65-72.

Stranger, C., Fombonne, E., Achenbach, T.M., 1994. Epidemiological comparisons of American and French children: parent reports of problems and competencies for ages 6-11. European Child and Adolescent Psychiatry. 3, 16-28.

Taylor, D.R., Poulton, R., Moffitt, T., Ramankutty, P., Sears, M., 2000. The respiratory effects of cannabis dependence in young adults. Addiction. 95, 1669-1677.

Taylor, R.D., Fergusson, D.M., Milne, B.J., Horwood, L.J., Moffitt, T.E., Sears, M.R., Poulton, R., 2002. A longitudinal study of the effects of tobacco and cannabis exposure on lung function in young adults. Addiction. 97, 1055-1061.

Timko, C., Cronkite, R.C., Swindle, R., Robinson, R.L., Sutkowi, A., Moos, R.H., 2009. Parental depression as a moderator of secondary deficits of depression in adult offspring. Child Psychiatry Hum Dev. 40, 575-588.

Weissman, M.M., Warner, V., Wickramaratne, P., Moreau, D., Olfson, M., 1997. Offspring of depressed parents: 10 years later. Archives of General Psychiatry. 54, 932-940. 
Table 1: Descriptive background characteristics of young (aged 22-35 years) adults and crude odds ratios (OR) of current cannabis use

\begin{tabular}{|c|c|c|c|c|}
\hline Descriptive Characteristics & $\mathbf{N}(\%)$ & Mean (+/-SD) & $\begin{array}{l}\text { Crude OR } \\
(95 \% \text { CI })\end{array}$ & p-value \\
\hline Age (years) & & $28.9(+/-3.68)$ & $0.93(0.89-0.96)$ & $<0.01$ \\
\hline \multicolumn{5}{|l|}{ Sex } \\
\hline Male & $454(41)$ & -- & $1.64(1.23-2.18)$ & $<0.01$ \\
\hline Female & $649(59)$ & -- & 1.0 & \\
\hline \multicolumn{5}{|l|}{ Socio-economic position } \\
\hline Low & $256(25)$ & -- & $2.11(1.53-2.89)$ & $<0.01$ \\
\hline Intermediate/High & $787(75)$ & -- & 1.0 & \\
\hline \multicolumn{5}{|l|}{ Living with partner } \\
\hline No & $442(41)$ & -- & $2.37(1.76-3.18)$ & $<0.01$ \\
\hline Yes & $631(59)$ & -- & 1.0 & \\
\hline \multicolumn{5}{|l|}{ Academic difficulties } \\
\hline Yes & 208 (19) & -- & $1.47(1.04-2.10)$ & 0.03 \\
\hline No & $884(81)$ & -- & 1.0 & \\
\hline Externalizing problems & & -- & & \\
\hline Yes & $129(12)$ & -- & $0.94(0.60-1.48)$ & 0.81 \\
\hline No & $964(88)$ & -- & 1.0 & \\
\hline Emotional Stability & & $4.38(+/-1.40)$ & $0.91(0.82-1.01)$ & 0.07 \\
\hline \multicolumn{5}{|l|}{ Parental smoking } \\
\hline Yes & $330(31)$ & -- & $1.08(0.79-1.48)$ & 0.49 \\
\hline No & $728(69)$ & -- & 1.0 & \\
\hline \multicolumn{5}{|l|}{ Parental gender } \\
\hline Male & $754(68)$ & & -- & -- \\
\hline Female & $349(32)$ & & -- & -- \\
\hline Parental divorce & & -- & & \\
\hline Yes & $154(15)$ & -- & $1.60(1.08-2.37)$ & 0.02 \\
\hline No & $889(85)$ & -- & 1.0 & \\
\hline Mean age at divorce (yrs) & & $17(+/-5.82)$ & -- & -- \\
\hline \multicolumn{5}{|l|}{ Parental depression } \\
\hline Yes, at least twice & $324(30)$ & & $1.40(1.03-1.90)$ & 0.03 \\
\hline Never or once & $774(70)$ & & 1.0 & \\
\hline \multicolumn{5}{|l|}{$\begin{array}{l}\text { Parental depression and divorce } \\
\text { status }\end{array}$} \\
\hline No divorce/depression & $247(24)$ & -- & $1.38(0.99-1.96)$ & 0.08 \\
\hline Divorce/no depression & $92(9)$ & -- & $1.55(0.94-2.57)$ & 0.09 \\
\hline Divorce/depression & $61(6)$ & -- & $2.31(1.31-4.06)$ & $<0.01$ \\
\hline No divorce/no depression & $642(61)$ & -- & 1.0 & \\
\hline
\end{tabular}


Table 2. Adjusted relative odds of young adult (aged 22-35 years) current cannabis use ( $\mathrm{N}=918)$

\begin{tabular}{|c|c|c|}
\hline Descriptive Characteristics & Adjusted OR (95\%CI) & p-value \\
\hline Age (years) & $0.95(0.90-1.00)$ & 0.06 \\
\hline \multicolumn{3}{|l|}{ Sex } \\
\hline Male & $1.44(1.03-2.01)$ & 0.03 \\
\hline Female & 1.0 & \\
\hline \multicolumn{3}{|l|}{ Socio-economic status } \\
\hline Low & $1.37(0.93-2.04)$ & 0.11 \\
\hline Intermediate/High & 1.0 & \\
\hline \multicolumn{3}{|l|}{ Living with partner } \\
\hline No & $1.91(1.34-2.71)$ & $<0.01$ \\
\hline Yes & 1.0 & \\
\hline \multicolumn{3}{|l|}{ Academic difficulties } \\
\hline Yes & $1.27(0.82-1.97)$ & 0.28 \\
\hline No & 1.0 & \\
\hline \multicolumn{3}{|l|}{ Parental smoking } \\
\hline Yes, & $1.06(0.74-1.52)$ & 0.75 \\
\hline No & 1.0 & \\
\hline \multicolumn{3}{|l|}{ Parental gender } \\
\hline Male & $1.22(0.85-1.76)$ & 0.27 \\
\hline Female & 1.00 & \\
\hline \multicolumn{3}{|l|}{ Parental divorce } \\
\hline Yes & $1.50(0.97-2.31)$ & 0.07 \\
\hline No & 1.0 & \\
\hline \multicolumn{3}{|l|}{ Parental depression } \\
\hline Yes, at least twice & $1.42(1.00-2.01)$ & 0.05 \\
\hline Never or once & 1.0 & \\
\hline
\end{tabular}


Table 3. Adjusted relative odds of young adults (aged 22-35 years) being current cannabis users $(\mathrm{N}=918)$ : Combined variable of parental divorce and depression

\begin{tabular}{lcc}
\hline Descriptive Characteristics & Adjusted OR (95\% CI) & p-value \\
Age (years) & $0.95(0.90-0.99)$ & 0.06 \\
Sex & & \\
$\quad$ Male & $1.46(1.04-2.03)$ & 0.03 \\
$\quad$ Female & 1.0 & 0.10 \\
Socio-economic status $\quad$ & \\
$\quad$ Low & $1.39(0.94-2.06)$ & \\
$\quad$ Intermediate/High & 1.0 & \\
Living with partner & & \\
$\quad$ No & $1.91(1.35-2.71)$ & \\
$\quad$ Yes & 1.0 & 0.29 \\
Academic difficulties & & \\
$\quad$ Yes & $1.27(0.82-1.96)$ & 0.76 \\
$\quad$ No & 1.0 & \\
Parental smoking & & \\
$\quad$ Yes & $1.06(0.74-1.51)$ & 0.28 \\
$\quad$ No & 1.0 & \\
Parental gender & & 0.14 \\
$\quad$ Male & $1.22(0.85-1.75)$ & 0.31 \\
$\quad$ Female & 1.00 & 0.01 \\
Parental depression and divorce status & & \\
$\quad$ No divorce/depression & $1.34(0.90-1.99)$ & \\
$\quad$ Divorce/no depression & $1.34(0.79-2.43)$ & \\
$\quad$ Divorce/depression & $2.38(1.26-4.48)$ & \\
$\quad$ No divorce/no depression & 1.00 & \\
$\quad$ & & \\
\hline
\end{tabular}

